\title{
Changes in attitudes towards gender and sexuality amongst trainee Healthcare Professionals
}

\author{
Laura Alonso Martínez ${ }^{1}$, María Fernández Hawrylak ${ }^{2}$ and Simon Forrest ${ }^{3}$ \\ University of Burgos ${ }^{1}$, University of Burgos ${ }^{2}$ and Durham University ${ }^{3}$
}

\begin{abstract}
Healthcare professions are centrally involved in the care of patients and families, the attitudes towards sexuality displayed nurses are important in terms of patient comfort, the accessibility and acceptability of care. This study aimed to assess whether the attitudes and competencies towards sexuality acquired during a Spanish Nursing Degree (2017-2018) are sufficient to instil confidence and competency in these trainees ahead of their move into professional practice. The study sought to examine the impact of current provision within the nursing program via survey with a self-completion questionnaire comparing analysis of results for 101 first-year students with 87 fourth-year students. We deployed the Scale of Attitudes towards Sexuality and the Double Standard Scale as measures. The 187 participants, 24 males and 163 females, ranged between 18 and 60 years old $(M=21.21$, $S D=5,48)$. A Mann-Whitney tests proved to be significant per course in attitudes towards sexuality, $U=3625.50, z=-1.95, p=.048$ and in adherence to gender roles, $U=3560.50, z=-2.13$, $p=.034$. These findings indicated that fourth-year students have more positive attitudes towards sexuality and less rigid adherence to gender roles. In addition, significant positive differences were obtained in a lower adhesion of gender roles in students over 20 years, $U=3282.00, z=-4.49, p<.001$. These results are suggestive that participation in this Nursing Degree had positive impact on attitudes towards sexuality. However, difference may be due to generational changes in attitudes. Further research is required to assess the education influence on healthcare professionals with larger samples, in order to obtain results that give a scientific consistency theory.
\end{abstract}

Keywords: Sexual Gender roles; Healthcare personnel; Sexual attitude; Sexual behaviour; Sexuality education. 